\title{
Awareness of Nurses Regarding Hemodialysis Complications
}

\author{
Seham Ahmed Ali ${ }^{1}$, Zienab Abd El-latif Mahammad ${ }^{2}$, Sahar Ali Abd El-mohsen ${ }^{3 .}$ \\ 1. B.SC. Nursing, Faculty of Nursing, Assiut University, Assiut, Egypt. \\ 2. Professor, Medical-Surgical Nursing Department, Faculty of Nursing, Assiut University, Asssiut, Egypt. \\ 3. Lecturer, Medical-Surgical Nursing Department, Faculty of Nursing, Assiut University, Assiut, Egypt.
}

\begin{abstract}
The aim of this study was to assess the nurse's awareness regarding hemodialysis complications. Subjects and Methods: A descriptive research design was utilized to conduct this study. This study was carried out at the hemodialysis unit in Manfalut central Hospital, Manfalut city - Assiut.The study sample consisted of nurses 35 nurses; ( males and females) working in the hemodialysis unit at Manfalut central Hospital, age ranges between 18 - 55 years and agreed to participate in the study. Self-administered questionnaire sheet was utilized to collect data pertinent to the study with the following parts; Part 1: "Nurse's sociodemographic characteristics", Part 2: "Nurse's awareness regarding hemodialysis practices", Part 3: "Nurse's awareness regarding hemodialysis complications". Results: (88.6\%) of the studied nurses were having good level of knowledge regarding hemodialysis complications and $(11.4 \%)$ of them were having poor knowledge level. Most of the studied nurses were females and their age ranged from (18-27) years. Conclusion: There was a highly statistically significant difference between nurse's knowledge regarding hemodialysis complications with their years of experience. Recommendations: Increase awareness of nurses through attending scientific meetings and conferences is important to keep the nurses pace with the rapidly growing wealth of knowledge and practice regarding hemodialysis for preventing its complications.
\end{abstract}

\section{Key words: Awareness, Nurses, Hemodialysis \& Complications.}

\section{Introduction}

Renal failure distinct as a systemic and a final pathway of many different kidney and urinary tract diseases. Renal failure results when the kidneys cannot remove the body's metabolic wastes or perform their regulatory functions. (Janice \& Kerry, 2014) Renal failure also defined as an illness while the kidney's incapability to filter wastes from the blood occurs suddenly and usually reversible or chronic and develops slowly over time because of permanent damage. (Farlex, 2012).

A process called dialysis, which is a life-preserving treatment, may replace renal function. Dialysis considers a drive of fluid and particles through a semipermeable sheath from one side to another. There are two main kinds of dialysis: heamo \& peritoneal dialysis (Hinkle \& Cheever, 2014). Hemodialysis (HD) is the greatest public method of dialysis. The HD is the process of removing metabolic waste and water from blood by a semipermeable membrane by a machine; this machine is often referred to as an synthetic kidney (Rosner, 2010).

Hemodialysis has evolved into a relatively harmless technique; however, dialysis complications mainly accompanied with it, some of which may be life threatening. Hypotension consider the commonest(20-50\%) acute complication of HD, then muscle cramps (20\%), nausea and vomiting (5-15\%), dialysis disequilibrium (10-20\%), headache (5\%), chest pain (2-5\%), itching (5\%), fever and chills less than one percentage, also arrhythmias, hemorrhage, hypoglycemia and blood-membrane interaction like the first use syndrome and acute hemolysis. (Prabhakar et al., 2015).

The dialysis nurse consumes the vital role in assessing, monitoring, also supporting and educating the patient. During dialysis, the patient, the dialyzer, and the dialysate have need of continuous checking for the reason that numerous complications may arise. (Hinkle \& Cheever, 2014).

The nurse should calculate fluid status previously the dialysis begins; Blood pressure, weight, temperature, lung \& heart sounds and peripheral edema, evaluate vascular access condition, and overall skin state. The ultrafiltration of weight that resulted from fluid accumulation, which should be removed and described by identifying the alteration between previous dialysis weight and the existing pre-dialysis weight. (Ostermann et al., 2012).

During HD, the nurses should measure the patient's vital signs every half and full hour because BP fluctuations may occur rapidly. In addition, body alignment should observe, change the patient's position frequently. Also, it's very important to screen nausea and vomiting occurrences during the dialysis procedure. Assess bleeding signs by taking clotting time an hour prior detachable from the machine. The patient's clotting time should be 
observed at a half to one an half hour during the session. (Ali, \& Gray-Vic krey, 2011).

After dialysis, any vascular access bleeding or difference in the patient's weight must be detected. The main nurse role is to assess if there any problems and irritating to diminish trauma or any extreme pressure on the access. In addition to assessing for an aneurysm to prevent its rupture or leading it to bleed which occurs when the nurse assesses the blebs or bulging of the vascular access. The nurse should screen blood urea nitrogen (BUN) creatinine, hematocrit, serum electrolytes and hemoglobin for patients experiencing dialysis. (Rushing, 2010)

\section{The Significance of the Study}

Nurse role is very important and do great efforts in prevention and early detection of HDcomplications, and from the researchers clinical experience in Manfalut central hospital; it has been observed that nurses working at HDs unit had lack of knowledge regarding HD complications, so this study targeted those nurses in an attempt to assess their awareness toward the complications of dialysis.

\section{The Aim of the Study}

The aim of this study was to assess nurse's awareness regarding hemodialysis complications.

\section{Research question}

What is the degree of nurse's awareness regarding hemodialysis complications?

\section{Subjects \& Methods \\ Research design}

A descriptive research design was used to meet the aim of the study.

\section{Setting}

The present study was accompanied at the dialysis unit in Manfalut central Hospital, Manfalut city Assiut.

\section{Subjects}

The study sample consisted of all available nurses (35 nurses; males and females) working in the hemodialysis unit at Manfalut central hospital, age ranges between 18 - 55 years.

Tool of data collection: One tool established by the researcher to collect the necessary data for this study after revising national and international literature under the guidance of supervisors.

Tool: Self-administered hemodialysis awareness questionnaire sheet; this tool was utilized to assess nurse's awareness regarding HD procedure and its complications, this tool included three parts:-

Part 1: Nurse's sociodemographic characteristics; which aim was to collect personal and social nurse's information included the following: their age, gender, marital status, experience years and education level.
Part 2: Nurse's awareness regarding hemodialysis practices; aimed to assess nurse's awareness about HD procedure as the following knowledge; the worth of washing hands between patients, before contact with the patient, the nurse should wear gloves, during insertion of the catheter must using sterile technique, checking if there are any infection signs at vascular access site, check function of vascular access site, importance of monitoring blood pressure through dialysis procedure. Also, the necessity of vital signs checking every half and full hour, catheter insertion accurately, the component of dialysate solution, set the speed of the bloodstream through the circuit set of dialysis, importance of measuring the patient weight pre and post dialysis, types of vascular access site, trade with any machine's alarms, personal protective equipment (PPE) importance which used in the unit especially for Hepatitis patient, and necessity of documenting machine setting and each nursing procedure during and after haemodialysis.

Part 3: Nurse's awareness regarding haemodialysis complications; which aim was to gather data for nurse's awareness regarding haemodialysis complications, as; air embolism, treatment of muscle cramp, dealing with changes in blood pressure, correction of a problem related to clotted dialysis, chest pain and shortness of breath, precautions when dealing with hepatitis patient and management of blood loss during dialysis.

\section{Scoring system:}

Nurse's awareness regarding haemodialysis procedure and complications, it included 22 questions that use a 3-point according to Likert scale. Scores to each item were between 1 and 3 points as follows; (I know, Uncertain, and do not know). The range of total scores lie between (22-66), nurses were classified as : Having adequate awareness at $60 \%$ or more of the range of total score or inadequate awareness at below $60 \%$.

\section{Methods of data collection}

- The research reviewed the national and international literature on the numerous sides of the problem using articles, books, and magazines.

- The content validity of the used tool to evaluate its easiness, applicability and understanding by 5 experts in the medical-surgical nursing field.

- An official authorization from the chief of authorized administration in Manfalut central hospital.

- Explaining the purpose and nature of the existing study to the studied sample before getting the oral permission for voluntary sharing. The right to withdraw from the study at any time, and for whatever reason.

- A pilot study was applied on four nurses (10\%) to evaluate tool applicability and clarity.

- An initial interview by the researcher to introduce herself to start a communication to facilitate the 
implementation of the tool was done before starting the research.

- Each nurse interviewed individually with the researcher for filling out the tool.

- The nurse's knowledge and awareness were assessed using the study tool that previously mentioned by the researchers.

Ethical considerations

- Obtain research approval from Faculty of Nursing Ethical Committee.

- No risk for the study subjects during the application of the research.

- The study followed public ethical principles in clinical research.
- Oral consent obtained from participated nurses, after explaining the nature and purpose of the study.

- Confidentiality and anonymity were secure.

- Study subject had the right to refuse participation and withdrawing from the study.

- The privacy of the study subject was considered during data collection.

\section{Statistical analysis}

Data entry and data analysis using SPSS version 19 (Statistical Package for Social Science). Data were presented as; (number- percentage (\%)- mean and standard deviation( $\mathrm{Sd})$-Chi-square test was used for qualitative variables. P-value considered statistically significant when $\mathrm{P}<0.05$.

\section{Results}

Part I: Demographic characteristics of the studied nurses.

Table (1): Distribution of the nurses regarding demographic characteristics $(n=35)$.

\begin{tabular}{|c|c|c|}
\hline Variables & N. & $\%$ \\
\hline \multicolumn{3}{|l|}{ Age groups } \\
\hline $18-<28$ years & 22 & 62.9 \\
\hline $28-<38$ years & 8 & 22.9 \\
\hline 38 years and more & 5 & 14.3 \\
\hline Total & 35 & 100 \\
\hline \multicolumn{3}{|l|}{ Gender } \\
\hline Male & 6 & 17.1 \\
\hline Female & 29 & 82.9 \\
\hline \multicolumn{3}{|l|}{ Marital status } \\
\hline Single & 4 & 11.4 \\
\hline Married & 31 & 88.6 \\
\hline \multicolumn{3}{|l|}{ Level of education } \\
\hline Secondary nursing school & 17 & 48.6 \\
\hline Nursing institute & 17 & 48.6 \\
\hline College of nursing & 1 & 2.9 \\
\hline \multicolumn{3}{|l|}{ Years of experience } \\
\hline Less than 1year & 1 & 2.9 \\
\hline $1-5$ years & 13 & 37.1 \\
\hline $5-10$ years & 14 & 40.0 \\
\hline $10-20$ years & 7 & 20.0 \\
\hline
\end{tabular}

Part II: Nurse's awareness regarding hemodialysis practice.

Table (2): Percentage distribution for nurse's awareness regarding hemodialysis practice $(n=35)$.

\begin{tabular}{|l|c|c|c|c|c|c|}
\hline \multirow{2}{*}{ Variables } & \multicolumn{5}{c|}{ Uncertain } & \multicolumn{2}{c|}{ Don't know } \\
\cline { 2 - 6 } & \multicolumn{2}{|c|}{ Know } & \multicolumn{2}{c|}{ Unc } & N. & \% \\
\cline { 2 - 6 } & $\mathbf{N}$ & $\mathbf{\%}$ & $\mathbf{N}$. & $\mathbf{\%}$ & - & - \\
\hline - washing hands importance between patients and another. & 35 & 100 & - & - & - & - \\
\hline -putting gloves before dealing with the patient. & 35 & 100 & - & - & - & - \\
\hline -Using sterile technique during insertion of the catheter. & 34 & 97.1 & 1 & 2.9 & - & - \\
\hline -Assessing vascular access for infection signs. & 35 & 100 & - & - & - & - \\
\hline -Evaluating the vascular access site for functioning. & 35 & 100 & - & - & - & - \\
\hline -Importance of checking blood pressure through dialysis. & 35 & 100 & - & - & - & - \\
\hline -Necessity of checking vital signs every half to full hour & 30 & 85.7 & 5 & 14.3 & - & - \\
\hline
\end{tabular}




\begin{tabular}{|c|c|c|c|c|c|c|}
\hline \multirow[t]{2}{*}{ Variables } & \multicolumn{2}{|c|}{ Know } & \multicolumn{2}{|c|}{ Uncertain } & \multicolumn{2}{|c|}{ Don't know } \\
\hline & $\mathbf{N}$. & $\%$ & N. & $\%$ & N. & $\%$ \\
\hline -Catheter insertion accurately (placement). & 34 & 97.1 & 1 & 2.9 & - & - \\
\hline -The component of dialysate solution. & 23 & 65.7 & 12 & 34.3 & - & - \\
\hline $\begin{array}{l}\text {-Set the speed of the blood stream through the (circuit set } \\
\text { of dialysis). }\end{array}$ & 35 & 100 & - & - & - & - \\
\hline -Monitor the weight of patient before and after the dialysis. & 35 & 100 & - & - & - & - \\
\hline -Types of vascular access site. & 29 & 82.9 & 6 & 17.1 & - & - \\
\hline -Dealing with all alarms in the machine. & 29 & 82.9 & 6 & 17.1 & - & - \\
\hline $\begin{array}{l}\text {-Importance of (PPE) used in the unit especially for } \\
\text { hepatitis patient. }\end{array}$ & 35 & 100 & - & - & - & - \\
\hline $\begin{array}{l}\text {-Necessarily document machine setting and each nursing } \\
\text { procedure during and after hemodialysis. }\end{array}$ & 28 & 80 & 7 & 20 & - & - \\
\hline
\end{tabular}

N.B:- PPE; personal protective equipment.

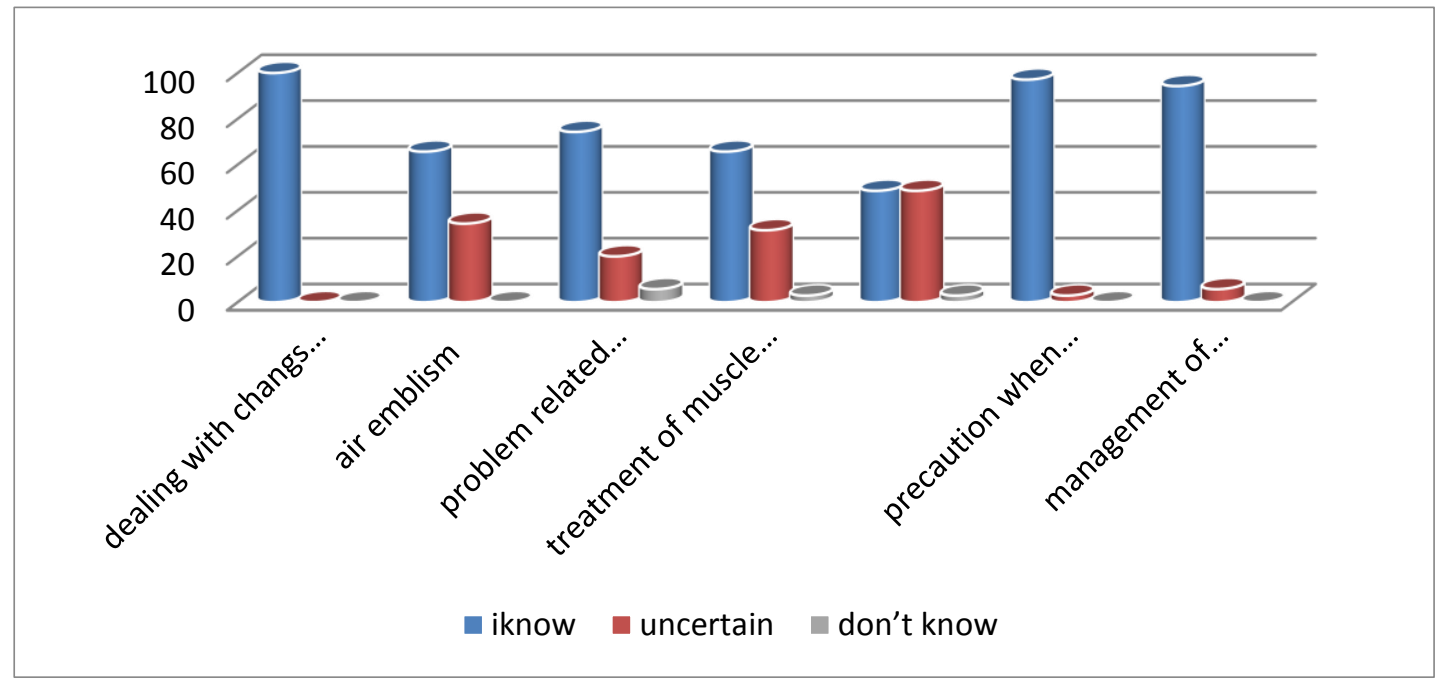

Fig.(1): Percentage distribution of nurses awareness regarding complications of hemodialysis.

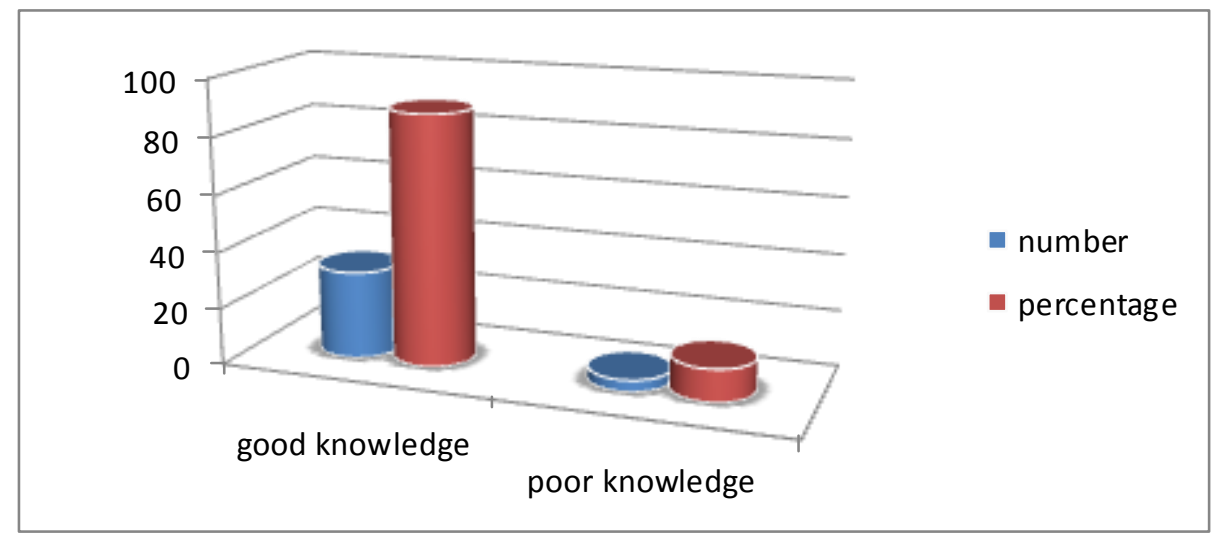

Fig. (2): percentage distribution of nurses level of knowledge about hemodialysis complications. 
Table (3): Relation between nurses knowledge regarding hemodialysis complications and their demographic data $(n=35)$.

\begin{tabular}{|c|c|c|c|c|c|c|}
\hline \multirow{3}{*}{ Variables } & \multicolumn{6}{|c|}{ Complication } \\
\hline & \multicolumn{2}{|c|}{$\begin{array}{c}\text { Good } \\
\text { knowledge }\end{array}$} & \multicolumn{2}{|c|}{$\begin{array}{c}\text { Poor } \\
\text { knowledge }\end{array}$} & \multirow[t]{2}{*}{ Total } & \multirow[t]{2}{*}{ P. value } \\
\hline & $\mathbf{N}$. & $\%$ & N. & $\%$ & & \\
\hline \multicolumn{6}{|l|}{ Age groups } & \multirow{4}{*}{0.42} \\
\hline $18-<28$ years & 19 & $54.3 \%$ & 3 & $8.6 \%$ & $22(62.9 \%)$ & \\
\hline $28-<38$ years & 8 & $22.9 \%$ & 0 & 0 & $8(22.9 \%)$ & \\
\hline 38years and more. & 4 & $11.4 \%$ & 1 & $2.9 \%$ & $5(14.3 \%)$ & \\
\hline \multicolumn{6}{|l|}{ Gender } & \multirow{3}{*}{0.45} \\
\hline Male & 6 & $17.1 \%$ & - & - & $6(17.1 \%)$ & \\
\hline Female & 25 & $71.4 \%$ & 4 & $11.4 \%$ & $29(82.9 \%)$ & \\
\hline \multicolumn{6}{|l|}{ Marital status } & \multirow{3}{*}{$0.00 *$} \\
\hline Single & 3 & $75.0 \%$ & 1 & $25.0 \%$ & $4(100 \%)$ & \\
\hline Married & 28 & $90.3 \%$ & 3 & $9.7 \%$ & $31(100 \%)$ & \\
\hline \multicolumn{6}{|l|}{ Level of education } & \multirow{4}{*}{0.52} \\
\hline Secondary nurses school & 16 & $45.7 \%$ & 1 & $2.9 \%$ & $17(48.6 \%)$ & \\
\hline Nursing institute & 14 & $40.0 \%$ & 3 & $8.6 \%$ & $17(48.6 \%)$ & \\
\hline College of nursing & 1 & $2.9 \%$ & - & - & $1(2.9 \%)$ & \\
\hline \multicolumn{6}{|l|}{ Years of experience } & \multirow{5}{*}{$0.00 * *$} \\
\hline Less than 1year & - & - & 1 & $2.9 \%$ & $1(2.9 \%)$ & \\
\hline $1-5$ years & 10 & $28.6 \%$ & 3 & $8.6 \%$ & $13(37.1 \%)$ & \\
\hline $5-10$ years & 14 & $40.0 \%$ & - & - & $14(40.0 \%)$ & \\
\hline $10-20$ years & 7 & $20.0 \%$ & - & - & $7(20.0 \%)$ & \\
\hline Total & 31 & $88.6 \%$ & 4 & $11.4 \%$ & \multicolumn{2}{|c|}{$35(100 \%)$} \\
\hline
\end{tabular}

Table (1): Showed that more than half of nurses' ages $(62.9 \%)$ ranged from $(18-27)$ years. Regarding gender $(82.9 \%)$ of them were females. Regarding marital status $(88.6 \%)$ of them were married, about one half $(48.6 \%)$ had diploma of nursing or institute of nursing and only one nurse had college of nursing. Regarding nurse's experience $(40 \%)$ of them their experience years ranged from six to ten years

Table (2): Proved that the most of nurses (92.8\%) had good knowledge in most of the items related to dialysis procedure.

Table (3): This table shows that there was a highly statistically significant difference between nurse's knowledge regarding hemodialysis complications and the marital status, and their years of experience $\mathrm{P}<0.00$.

Fig (1): This figure illustrates that nurses were aware most regarding dealing with blood pressure changes $(100 \%)$, precautions when dealing with hepatitis patient $(97.1 \%)$, and management of rupture blood loss during dialysis $(94.1 \%)$.

Fig (2): This figure illustrates that most of nurses (88.6\%) were aware regarding complications of dialysis.

\section{Discussion}

From the existing study results, there was a large percentage of nurses' age extended from 20 to $<30$ years, this comes as per Ahmed, (2011) who escorted his research entitled "the effect of designed nursing protocol on nurse's knowledge \& practice regarding HD patients" and discovered that the ages of studied nurses extended from 20 to 29 years. This study result is also in agreement with Abd-Alfatah's , (2014) consider which was corresponding in Nephrology of Pediatric and Dialysis Unit in Children Assiut University Hospital and discovered that their ages ranged from 20- to less than 30 years. While this study result dis agreed with El-Moghazy (2013) who expressed that greater part of attendants matured $>30$ years of age.

Large portion of the nurses were females which may be identified with the propensity of females to enter the nursing schools in Egypt and there is no nursing schools for males at Manfalut city so males think that its hard to enter nursing schools at neighboring urban communities; this comes in concurrence with Ebrahim et al., (2016) whom described that the majority of nurses were females, and this finding was in the same line with Abdelsatir (2013) a study that was conducted at Khartoum State; who stated that most of nurses were females, while this study denied 
with Jafar (2012) which was carried at Baghdad teaching hospitals, and detailed that greater than $1 / 2$ of the sample were males.

The results also presented that most of nurses was married, and this finding agreed with Jafar (2009) who originate in his study $>1 / 2$ of the study sample were married.

Regarding experiences' years; it was noticed that more than one third of the nurses their experience ranges from six to ten years. This study agreed with Ahmed, (2011) who reported that the most of the studied nurses their experience ranged from 5 to $<10$ years. The present study result disagreed with Jafar (2012) who stated that more than more than half $(63.3 \%)$ of nurses experience's years varied from 1 to $<5$ years.

Concerning HD complications, the current study's results displayed that all of nurses had adequate awareness concerning of HD procedure. In addition, the majority of sample had adequate awareness in six items but a small number of nurses had moderate awareness in one item.

Regarding the nurses' awareness about HD procedure, the most of studied nurses had adequate awareness level. This may explained that; most of nurses experience's years were not less than ten years. This agreed with Abd-Alfatah, (2014) who stated that the studied nurses were better in their total level score of awareness.

The contemporary results revealed that the large percentage nurses had adequate awareness about hemodialysis complications. Moreover, the least percentage had poor knowledge level about complications of theHD.

From present study, a highly statistically significant difference found between nurse's awareness about complications of HD and experience's years, P value $\left(0.00^{* *}\right)$. This finding agreed with the result of Ahmed, (2011) which identified that there was a statistically significant difference between nurse's awareness scores and experience's years.

In addition, regarding HD complications and marital status, the results showed that there was a statistically significant difference between the scores of nurses' awareness with $\mathrm{P}$ value $\left(0.00^{*}\right)$.

As concerning to the relationship between nurse's awareness level about hemodialysis complications and age, the present study discovered that there was no a statistically significant difference this was not similar to Abd-Alfatah, (2014) who stated that there was a statistically significant difference between nurse's awareness level and age in years.

\section{Conclusion}

Centered on the finding of the existent study, it is concluded that:
Majority of the studied nurses their age group ranged from (18-27) years, females and married, about one half had diploma of nursing or institute of nursing and only one nurse had college of nursing; and less than half of them their experience's years ranged from $6: 10$ years. The studied nurses have inadequate awareness regarding hemodialysis practice in item the component of dialysate solution and adequate awareness concerning the hemodialysis complications in items of dealing with changes in blood pressure, precautions when dealing with hepatitis patient and management of blood loss through hemodialysis.

\section{Recommendations}

As the findings of the existing study, the following recommended:-

1- Availability of manual procedures for nurses to be aware of handling any problems that may arise in the unit.

2- In-service training programs should frequently be accompanied in the unit for continuous up dating and regeneration of nurse's knowledge and skills to maintain and improve level of awareness and practice.

3- Further researches should be done on a large sample focusing on their practice to generalize the results of this study regarding of their knowledge\& its reflection on their practice.

\section{References}

1. Janice L., \& Kerry H., (2014): Brunner \& Suddarth's textbook of medical-surgical nursing, chapter $53,13^{\text {th }}$ (ed) Wolters Kluwer Health, Lippincott Williams \& Wilkins, Pp. 3170 - 3172, 3228, 3241.

2. Farlex P., (2012): Medical Dictionary. Farlex

3. Hinkle J.,. \& Cheever K., (2014): Brunner \& Suddarth's Text Book of Medical Surgical Nursing. $13^{\text {th }}$ (ed), Wolters Kluwer Lippincott, Wiliams \& Wilkins, chapter 43. Pp. 1259 1279

4. Rosner M., (2010): Hemodialysis for the non nephrologist, south Med J 98:785.

5. Prabhakar, Rana G., Shivendra S., Surendra S., \& Tauhidul A., (2015): Spectrum of intradialytic complications during hemodialysis and its management: Saudi Journal of Kidney Disease and Transplantation, 26 (1):Pp. 168172.

6. Ostermann M., Dickie H., \& Barrett N., (2012): Renal replacement therapy in critically ill patients with acute kidney injury: when to start. 
7. Ali B., \& Gray-Vickrey P., (2011): Limiting the damage from acute kidney injury, Nursing 41 (3): 22, 2011.

8. Rushing, J., (2010): Caring for a patient's vascular access for hemodialysis, Nursing Management (Springhouse). Issue: Volume 41(10), October 2010, by Lippincott Williams \& Wilkins, Inc. p 47.

9. Ahmed G., (2011): Effect of Designed Nursing Protocol on Nurse's Knowledge and Practice Regarding Hemodialysis Patients. Unpublished Master Thesis, Department of Medical Surgical Nursing Science. Faculty of Nursing, Asuit University.

10. Abd-Alfatah A., (2014): Assessment of Nurses' Knowledge and Practice Related to Nursing Care of Children Undergoing Hemodialysis at Assiut City. Thesis, B.Sc. Nursing, Faculty of nursing, Pediatric nursing department, Assiut University.

11. EL-moghazy G., (2013): Nurses Knowledge and Practice Regarding Intradialytic Complications for Hemodialysis Patient. Journal of American Science, 9: 11, 2013.

12. Ebrahim A., Ibrahim M., \& Taha N., (2016): Nurses' Knowledge and Practice Regarding Care for the Patients during Hemodialysis. Med. J. Cairo Univ., Vol. 84, No. (1):Pp. 1135-1141.

13. Abdelsatir S., (2013): Evaluation of Nurses Awareness and Practice of Hemodialysis Access Care in Khartoum State, Sudan. Arab Journal of Nephrology and Transplantation, 6: 119-21, 2013.

14. Jafar B., (2009): Assessment of Nurses' knowledge toward Hepatitis B Virus in Hemodialysis Unit. (Thesis) University of Baghdad, College of Nursing, 2009.

15. Jafar B., (2012): Evaluation of Nurses' Practices throughout Hemodialysis Treatment for Patients in hemodialysis unit at Baghdad teaching hospitals.Kufa Jurnal for nursing science vol 2, No 2 (2012). 